\title{
AS IDENTIDADES NEGRAS DA EJA EM DIÁLOGO COM A (RE)EDUCAÇÃO DAS RELAÇÕES ÉTNICO-RACIAIS
}

Luís Carlos Ferreira ${ }^{1}$

Euclides André Musdna Malú ${ }^{2}$

\section{RESUMO}

O propósito do texto é discutir o processo de reeducação das relações étnico-raciais na educação de jovens e adultos, a partir das identidades negras no cotidiano escolar da EJA. É um estudo de abordagem qualitativa em que recorremos à pesquisa bibliográfica, cujos referenciais estão pautados em documentos legais como a Lei 10.639/2003, Diretrizes Curriculares Nacionais das Relações ÉtnicoRaciais e para o Ensino de História e Cultura Afro-Brasileira e Africana, Censo Educacional de 2019; além do aporte teórico em Falola (2020), Oyêwùmí (2018), Gomes (2005), Odé Inocêncio (2001), Schwarcz (2012), dentre outros que fundamentam a discussão. No primeiro momento, consideramos os dados oficiais de pardos e pretos informados nas matrículas da EJA, como resultado do Censo Educacional (2019) e seus efeitos na produção das identidades e reconhecimento das culturas africanas e afro-brasileiras. No segundo momento, problematizamos a questão da reeducação para as relações étnico-raciais reconhecendo que, passados dezessete anos de implementação da primeira versão da Lei 10.639/2003, não foram suficientes para a ressignificação dos conhecimentos potenciais de África e da diáspora. Por fim, é necessário continuarmos a discutir os aspectos ligados à dimensão da corporeidade, africana e afrobrasileira, tornada invisível e negada nas salas de aula da EJA; às múltiplas abordagens das religiosidades de matriz africana; às inúmeras manifestações e práticas culturais de raiz africana

\footnotetext{
${ }^{1}$ Doutor em Políticas Públicas e Formação Humana. Professor Adjunto da Universidade da Integração Internacional da Lusofonia Afro-brasileira (UNILAB-CE). ORCID: https://orcid.org/0000-0003-2695-6206. E-mail: luisferreira@unilab.edu.br

${ }^{2}$ Bacharel em Humanidades (UNILAB-CE). Licenciando em Pedagogia (UNILAB-CE). Membro do Grupo de Pesquisa: Observatório Vozes da EJA Brasil-África. ORCID: https://orcid.org/0000-0003-4311-1336. E-mail: euclidesandremalu@gmail.com
} 
conectadas com as experiências de seus descendentes brasileiros, sem esgotarmos o debate.

Palavras-chave: Relações Étnico-Raciais. Identidades africanas e afro-brasileiras. Educação de Jovens e Adultos.

\section{EJA'S BLACK IDENTITIES IN DIALOGUE WITH THE (RE)EDUCATION OF ETHNIC-RACIAL RELATIONS}

\section{ABSTRACT}

The purpose of the text is to discuss the process of re-education of ethnic-racial relations in the education of young people and adults, based on black identities in the daily life of EJA. It is a study with a qualitative approach in which we resorted to bibliographical research, whose references are based on legal documents such as Law 10.639/2003, National Curriculum Guidelines for Ethnic-Racial Relations and for the Teaching of Afro-Brazilian and African History and Culture, Census 2019 Educational; in addition to theoretical contributions in Falola (2020), Oyêwùmí (2018), Gomes (2005), Odé Inocêncio (2001), Schwarcz (2012), among others that support the discussion. At first, we considered the official data of browns and blacks informed in EJA enrollments, as a result of the Educational Census (2019) and its effects on the production of identities and recognition of African and Afro-Brazilian cultures. In the second moment, we problematize the issue of re-education for ethnic-racial relations, recognizing that, seventeen years after the implementation of the first version of Law 10.639/2003, it was not enough for the resignification of the potential knowledge of Africa and the diaspora. Finally, it is necessary to continue to discuss aspects related to the dimension of corporeality, African and Afro-Brazilian, made invisible and denied in EJA classrooms; the multiple approaches to Africanbased religiosities; to the countless manifestations and cultural practices of African roots connected with the experiences of their Brazilian descendants, without exhausting the debate. 
Keywords: Ethnic-Racial Relations. African and Afro-Brazilian Identities. Youth and Adult Education.

\section{LAS IDENTIDADES NEGRAS DE EJA EN DIÁLOGO CON LA (RE) EDUCACIÓN DE LAS RELACIONES ÉTNICO-RACIALES}

\section{RESUMEN}

El propósito del texto es discutir el proceso de reeducación de las relaciones étnico-raciales en la educación de jóvenes y adultos, basado en las identidades negras en la vida cotidiana de EJA. Se trata de un estudio con enfoque cualitativo en el que se recurrió a la investigación bibliográfica, cuyas referencias se basan en documentos legales como la Ley 10.639 / 2003, Lineamientos Curriculares Nacionales para las Relaciones Étnico-Raciales y para la Enseñanza de la Historia Afrobrasileña y Africana y Cultura, Censo 2019 Educativo; además de aportes teóricos en Falola (2020), Oyêwùmí (2018), Gomes (2005), Odé Inocêncio (2001), Schwarcz (2012), entre otros que apoyan la discusión. En un primer momento, se consideraron los datos oficiales de pardos y negros informados en las inscripciones de EJA, como resultado del Censo Educativo (2019) y sus efectos en la producción de identidades y reconocimiento de las culturas africanas y afrobrasileñas. En un segundo momento, problematizamos el tema de la reeducación para las relaciones étnico-raciales, reconociendo que, diecisiete años después de la implementación de la primera versión de la Ley 10.639 / 2003, no fue suficiente para la resignificación del conocimiento potencial. de África y la diáspora. Finalmente, es necesario seguir discutiendo aspectos relacionados con la dimensión de la corporeidad, africana y afrobrasileña, invisibilizados y negados en las aulas de EJA; los múltiples enfoques de las religiosidades africanas; a las innumerables manifestaciones y prácticas culturales de raíces africanas conectadas con las vivencias de sus descendientes brasileños, sin agotar el debate.

Palabras clave: Relaciones étnico-raciales. Identidades africanas y afrobrasileñas. Educación de jóvenes y adultos. 


\section{INTRODUÇÃO}

Nos últimos anos, a questão da educação das relações étnicoraciais na Educação de Jovens e Adultos tem sido objeto de discussões nada definitivas, nem tampouco, acabadas, acerca da temática que envolve não somente a autoafirmação fenotípica nos registros oficiais do censo educacional, mas o que isso representa no contexto ampliado das identidades e culturas afro-brasileiras. É flagrante que a categoria racial definida e informada nas matrículas escolares da educação de jovens e adultos, demonstra não só o reconhecimento da negritude e a valorização da pessoa humana como também nos desafiam repensar a emblemática relação de distanciamento entre as identidades negras, os currículos da EJA e o cotidiano escolar da modalidade.

Sendo assim, o propósito do texto é discutir o processo de reeducação das relações étnico-raciais na educação de jovens e adultos, a partir das identidades negras presentes no cotidiano escolar da EJA.

Em um primeiro momento, consideramos os dados oficiais de pardos e pretos informados nas matrículas da EJA, como resultado do Censo Educacional (2019) e seus efeitos na produção das identidades e reconhecimento das culturas africanas e afrobrasileiras. No segundo momento, problematizamos a questão da reeducação para as relações étnico-raciais reconhecendo que, passados dezessete anos de implementação da primeira versão da Lei 10.639/2003, não foram suficientes para a ressignificação dos conhecimentos potenciais de África e da diáspora.

Buscamos as bases políticas e pedagógicas previstas nas normativas legais expressas na Lei 10.639/2003, em sua versão inicial, bem como nas Diretrizes Curriculares Nacionais Gerais da Educação Básica e nas Diretrizes Curriculares Nacionais para a Educação das Relações Étnico-Raciais e para o Ensino de História e Cultura AfroBrasileira e Africana, ambas do INEP/MEC, assim como na literatura especializada nesse debate educacional.

Nesse contexto, despertamos para as questões identitárias do

povo negro brasileiro, jovem ou adulto, negro e negra da modalidade, recuperando alguns aspectos ligados às culturas 
africanas e expressões africanas e afro-brasileiras. Não por acaso, reconhecemos o desafio árduo e complexo do currículo escolar que, ainda, invisibiliza, nega e hierarquiza a cultura negra.

A preocupação com a reeducação das relações étnico-raciais consiste na paridade dos conhecimentos ligados às culturas africanas e afro-brasileiras nos projetos político-pedagógicos e práticas educativas em face das identidades negras presentes nas salas de aula da EJA. Ao mesmo tempo, revelamos os desafios interpostos na efetividade dos currículos da modalidade, das diretrizes curriculares ${ }^{3}$ e da Lei $10.639 / 2003^{4}$ em consonância com as culturas africanas e afro-brasileiras vivificadas nas salas de aula.

Desse modo, as DCN's para a Educação das Relações ÉtnicoRaciais nos mostram que "não se trata de mudar um foco etnocêntrico marcadamente de raiz europeia por um africano, mas de ampliar o foco dos currículos escolares para a diversidade cultural, racial, social e econômica brasileira." (BRASIL, 2004, p.17).

\section{Identidades Negras na Educação de Jovens e Adultos}

Longe de tratarmos de determinismo biológico, nosso interesse pelas informações sobre o pertencimento racial nos dados das matrículas da EJA e, posteriormente, nos dados do censo educacional deve-se ao sentido político de como as pessoas se veem e se consideram em relação às suas histórias, experiências e culturas. Assim, consideramos um significativo avanço os dados do Censo da Educação Básica de 2019, em que mostram 75,8\% de pretos e pardos, matriculados no Ensino Fundamental e $67,8 \%$ de pretos e pardos, no Ensino Médio, com base nas autodeclarações nas matrículas. (BRASIL, 2020).

Por essa razão, faz-se necessário o diálogo entre as informações dadas pelos sujeitos da EJA no ato da matrícula e o

\footnotetext{
${ }^{3}$ Documento oficinal publicado em 17 de junho de 2004, pela Resolução № 1 que institui as Diretrizes Curriculares Nacionais para a Educação das Relações Étnico-Raciais e para o Ensino de História e Cultura Afro-Brasileira e Africana.

${ }^{4}$ Publicada em 9 de janeiro de 2003, a Lei 10.639/2003, Altera a Lei 9.394/1996 que estabelece as diretrizes e bases da educação nacional, para incluir no currículo oficial da Rede de Ensino a obrigatoriedade da temática "História e Cultura Afro-Brasileira."
} 
reconhecimento das identidades negras reveladas não somente nas características fenotípicas, traços físicos e biológicos, mas nas epistemologias africanas e afro-brasileiras encarnadas nos valores civilizatórios, ascendência negra, ancestralidade, incidências religiosas de matrizes africanas e afro-brasileiras e em outras relações culturais amplas e diversas, no processo de construção da igualdade racial.

O número nas matrículas e a consolidação estatística pela base de dados do Censo Educacional do INEP/MEC e de outros instrumentos de controle e acompanhamento dos estados e municípios, nos mostram a sensibilidade e a potência encorajadora de busca por igualdade racial quando a/o jovem e adultos, ao se matricular, se reconhece como negro e negra, na escola e fora dela, frente às inúmeras questões impostas pelo racismo estrutural e institucional, consequência da exclusão social. Ao mesmo tempo, desvela os muitos caminhos que precisamos percorrer para superar alguns dos mecanismos internos e silenciados praticados por uma "exclusão includente" (GENTILI, 2005), geradora da discriminação e do preconceito "invisíveis" aos processos educativos que passam no cotidiano das relações sociais.

Baseados em Schwarcz (2012, p.49), adotamos a categoria de raça social como "construções sociais, políticas e culturais produzidas nas relações sociais e de poder ao longo do processo histórico" como forma de avançarmos no debate acerca das identidades negras e do "re-conhecimento" explícito da negritude e do fortalecimento de vínculos, movimentos, construções, percursos e histórias que auxiliam na igualdade racial, na construção do ser negro e negra e, sobretudo, no acesso aos direitos humanos.

Não por acaso, nosso questionamento está concentrado na educação escolar, sobretudo, na modalidade da Educação de Jovens e Adultos no que se refere à reorganização curricular, às estruturas formais de ensino, metodologias e didáticas que (des)consideram os corpos negros, os valores ancestrais e espirituais, as presenças religiosas de matrizes africanas e afro-brasileiras, as tradições, os movimentos afrodiaspóricos e as referências africanas e afrobrasileiras que chegam às salas de aula. 
A abordagem fenotípica expressa nos corpos negros não nos parece suficiente para ampliação do debate em torno das culturas africanas, tampouco, merece ser isolada de um contexto mais amplo, pois os corpos carregam credenciais inscritas em valores, representações e significados que podem ser traduzidos na postura, no comportamento, nas formas de agir e pensar das pessoas. No caso, "trata-se de uma espécie de 'escrita viva ou vivificante' em que se imprimem as ressonâncias perceptivas e escavam os trilhos, com os sentidos, na existência humana". (MARTINS, 2015, p.164).

As características fenotípicas negras falam muito e importam quando nos referimos às questões raciais e, sobretudo, de pertencimento ao universo em que os corpos com seus signos próprios, denunciam o racismo visual. Não por acaso que, reforçamos o quanto as formas e representações visuais do corpo, no tipo e estilo de cabelo, no formato do nariz, nos riscos e expressões da boca, entre outras marcas, veiculadoras da beleza negra, implicam nos estereótipos dominadores do senso comum ligados ao belo, estético, aceitável etc.

Estudos de Odé Inocêncio (2001) nos orientam muito a respeito da identificação dos corpos visuais e todo sentido dado a um conjunto de signos que se diferenciam pela questão racial. Nesse percurso, destacamos que

é preciso que olhemos para este corpo não apenas como um território que demarca bem a diferença racial, um termômetro que indica as tensões cotidianas resultantes das desigualdades geradas pelo racismo. (ODÉ INOCÊNCIO, 2001, p. 192)

Recorremos ao passado e ao presente para olharmos a complexidade das culturas africanas, multidimensionais e diversas, com base nos significados e na relevância que explicam as nossas identidades negras, influências, heranças e legados de África e da diáspora, na constituição do povo negro brasileiro. É em torno do Atlântico que inúmeras contribuições têm sido dadas - ciência, literatura, artes cênicas, música, dança etc. --, principalmente, na formação da consciência humana em relação à riqueza e potência dos valores culturais como símbolo das diferenças. 
O legado histórico de dominação forçada pela Europa, ainda constitui parte da preocupação do povo africano em transformar a imagem de marginalização do continente e potencializar as credenciais e a cor, tornadas frágeis, em muitas regiões do mundo. Em outras palavras, carregamos o trágico processo de colonização que acentuou a busca por "recuperar o que lhes foi negado, modificar o que foi introduzido, reconectar a cultura e o desenvolvimento, apropriar-se do passado de modo a criar um futuro melhor, e defender o "particular" diante da ofensiva do "universal"". (FALOLA, 2020, p.88).

Nesse contexto em que as culturas importam, entendemos que existe um compromisso maior com as identidades africanas e afro-brasileiras, mantidas em constante dinâmica pelos processos de adaptação, transformação e mudança. Não é novidade que a culturas se renovam e se reconstroem como instrumento de resistência. Ao afirmamos, pensemos na dívida histórica, política e social por toda violação e consequências geradas pelo tráfico de escravos, na brutal devastação dos povos no continente e tantas outras marcas negativas ${ }^{5}$ deixadas pela civilização ocidental nas culturas locais e na identidade coletiva de África.

Com base na inserção das culturas africanas no debate educacional, na perspectiva das identidades negras da EJA, outras questões atravessam a discussão que não podem [e não devem] estar dissociadas da cultura, ou seja, as políticas econômicas, tecnológicas, científicas que carregam histórias, memórias, fundamentos enraizados na cultura que conduzem à produção de novos conhecimentos, modos de ser e de viver.

No caso dos jovens e adultos brasileiros que declaram suas autorreferências identitárias nas categorias raciais de pardos e pretos na escola da segunda chance, temos condições de analisar as mudanças culturais, a dinâmica dos movimentos de conscientização,

\footnotetext{
5 As consequências do colonialismo foram muito diversas e brutais em que as desigualdades sociais e educacionais foram agravadas pelo abandono de um passado para, assim, renascerem de um presente transformado pela imposição de línguas estrangeiras, a dominação religiosa, a desintegração cultural pela ruptura, subordinação, assimilação e imitação de valores, costumes, tradições e normas ocidentais. (FALOLA, 2020).
} 
o empoderamento da identidade negra e, principalmente, a educação [e reeducação] para as relações étnico-raciais. Nesse processo, tem sido fundamental aprender a superar o passado da colonização e potencializar a presença negra em diversos campos sociais, sobretudo, na educação servindo como elemento propulsor para a reformulação dos currículos escolares.

Reconhecemos que a educação escolar assume papel fundamental na superação positiva dos valores e afirmação da identidade africana e afro-brasileira, ao promover políticas institucionais internas e externas de recuperação da igualdade e dignidade do povo negro. Arriscamos dizer que, essa concepção se revela na ampliação do contingente de negros e negras que chegam às escolas da Educação de Jovens e Adultos. Embora estejamos tratando dos que reingressam tardiamente às salas de aula, os tempos são outros que não podem ser naturalizados ou passar despercebidos entre as razões do abandono e da exclusão no período próprio da idade escolar.

Nem, tampouco, podemos manter invisíveis, no caso específico, a constatação desses dados que nos revelam importantes transformações culturais e subjetivas dos corpos negros desses sujeitos, jovens e adultos, quando retornam seus estudos em busca de novas, e outras, oportunidades, expressam suas demandas e interesses por novas realidades.

Os valores encarnados na essência de cada pessoa, negro e negra, fundamentam as referências que dão sentido ao conhecimento de si e que ajudam na construção das diferenças raciais, religiosas, filosóficas, geracionais, sexuais, territoriais etc. Interseccionadas, essas referências ampliam as redes de diálogo coletivo e influenciam, positiva ou negativamente, na formação da identidade negra da EJA. Em outros termos, podemos dizer que tantos marcadores da diferença produzem sentidos e significados diferentes que nos auxiliam na produção de um olhar sobre as diferenças para os diferentes.

Vale lembrar de Boaventura de Souza Santos em uma de suas contribuições para o olhar sobre as diferenças, em que nos afirma que "temos o direito a ser diferentes quando a diferença nos 
inferioriza, temos o direito a ser diferentes quando a igualdade nos descaracteriza". (SANTOS, 1996, p.3).

Nessa perspectiva, a identidade cultural africana e seus reflexos na produção dos modos de ser e ver o mundo por diferentes sujeitos negros/as, dão mostras sensíveis entre as nossas referências culturais afro-brasileiras, resultando na transformação da consciência libertadora dos corpos e mentes, negros e negras que, social e culturalmente, habitam nos jovens e adultos que se reafirmam no jogo de forças políticas e culturais.

Sendo assim, somos afetados pelas culturas africanas em experiências diversas e, ao mesmo tempo, afetamos novas produções da cultura e da educação. É possível falarmos que as diferentes identidades construídas - não descobertas - dão significado ao jogo das diferenças, não pelas diferenças em si, mas o que elas representam em nossas consciências quando reconhecemos que, a partir do 'outro' constituímos nossas referências singulares.

Uma das razões para trazermos a questão das identidades consiste em problematizarmos os sujeitos a EJA em suas histórias, memórias, estilos e perspectivas de vida que somam às suas identidades políticas ao se enxergarem como negros e negras. Essa liberdade do sujeito em mergulhar, subjetivamente, em si, sendo capaz de reinterpretar sua essência, suas referências e culturas explicam as inesgotáveis tentativas de construções e/ou afirmações de negritudes.

Insistimos em tratar das referências que constituem o ' $e u^{\prime}$, singular e subjetivo de cada um, por entendermos que as relações entre os grupos sociais nos quais pertencemos, participamos e interagimos têm valiosa importância na construção de concepções pautadas nas diferenças, na aceitação, respeito e reconhecimento do 'outro'. Ao afirmarmos, Gomes (2005, p. 41) nos auxilia a pensar que:

A identidade não é algo inato. Ela se refere a um modo de ser no mundo e com os outros. É um fator importante na criação das redes de relações e de referências culturais dos grupos sociais. Indica traços culturais que se expressam através de práticas linguísticas, festivas, rituais, comportamentos alimentares e tradições populares, 
referências civilizatórias que marcam a condição humana.

A articulação dos conhecimentos ligados às culturas africanas e afro-brasileiras e suas influências na cultura escolar e, sobretudo, nos sujeitos negros e negras da escola de jovens e adultos, nos instiga a recorrer aos textos legais como o Parecer 03/2004, que dá origem às DCN's para Educação das Relações Étnico-Raciais e para o Ensino da História e Cultura Afro-Brasileira e Africana e a Lei 10.639/2003.

\section{As Diretrizes Curriculares em diálogo com as culturas africanas e afro-brasileiras}

Acreditamos nos avanços das políticas públicas de educação promovidas no ano de 2003 e assumimos o compromisso de incorporarmos práticas e experiências pedagógicas ligadas às referências legais instituídas pela implementação da Lei 10.639/2003 e a consequente alteração da Lei de Diretrizes e Bases da Educação Nacional No 9.394/1996, assim como na elaboração das Diretrizes Curriculares Nacionais para a Educação das Relações Étnico-Raciais e para o Ensino de História e Cultura Afro-Brasileira e Africana e tantas outras políticas reparadoras e de valorização das culturas africanas e afro-brasileiras.

Desse modo, a criação da Secretaria Especial de Políticas de Promoção da Igualdade Racial ${ }^{6}$ (SEPPIR) e, por conseguinte, da Política Nacional de Promoção da Igualdade Racial, colocaram no centro do debate educacional as questões do combate ao racismo, promoção da igualdade de oportunidades entre diferentes grupos étnicos, afirmação de direitos humanos fundamentais ao exercício da cidadania e, sobretudo, a luta pela eliminação das desigualdades raciais para a construção de uma sociedade democrática, justa e igualitária. (BRASIL, 2004).

Não temos dúvidas de que a militância do movimento negro e as iniciativas da sociedade civil exerceram [e ainda exercem] papel

\footnotetext{
${ }^{6}$ Em 2018, a Secretaria Especial de Políticas de Promoção da Igualdade Racial (SEPPIR) foi extinta pelo governo de Jair Bolsonaro, tornando-se um departamento dentro da Secretaria da Cidadania, ligada ao Ministério de Direitos Humanos (MDH).
} 
importante na construção de políticas públicas, curriculares, fundamentais na transformação da realidade educacional. Compreendemos, inclusive, que o ser negro e o declarar-se negro nos registros oficiais, como no caso das matrículas para ingresso na modalidade da educação de jovens e adultos, seja parte de um resultado da consciência política que vem sendo construída ao longo dos anos de luta por igualdade de direitos do povo negro.

Nesse trabalho, problematizamos a existência do público da EJA, em sua maioria constituída por mais negros e negras, frente os currículos educacionais, colonizados e carregados de saberes da branquitude, mesmo com todas as conquistas refletidas entre as políticas de educação. Contudo, o crescimento da população negra, jovens e adultos, autoafirmados na escola, expressa parte da libertação dos corpos e das mentes, conscientização, reflexão e ações que incluem, entre outras situações, a formação de atitudes, comportamentos, posturas e valores do orgulho de seu pertencimento étnico-racial, previstos nas diretrizes curriculares.

Por tantos motivos, arriscamos dizer que a autonomia, espontaneidade e a autenticidade das pessoas negras que expressam suas categorias raciais como pretas e pardas, não podem passar despercebidas nos currículos oficiais, tampouco, invisíveis no debate étnico-racial na escola [e fora dela]. Até que ponto as identidades negras presentes nas turmas e/ou escolas de Educação de Jovens e Adultos são representadas nos projetos políticos pedagógicos, propostas curriculares e nos conteúdos de ensino da modalidade? Sublinhamos que a resposta para essa indagação é tão complexa quanto a reflexão sobre o currículo da educação brasileira e as realidades obscuras e explícitas de racismo e exclusão escolar.

Entendemos o orgulho de se manifestar negro e negra no primeiro rito de reingresso na escola - a matrícula - como um passo importante para o fortalecimento e a legitimidade do direito de negros e negras serem negros e negros, ou seja, exercerem suas negritudes na escola [e fora dela] e provocarem mudanças nos saberes e fazeres escolares, na perspectiva da produção de currículos integrados às diferentes culturas que deem sentido aos avanços positivos da história. 
Pelo tempo decorrido de normatização da política, chamamos atenção para o fato de que não cabe pensar em projetos pedagógicos que não sejam políticos, em sua essência. Muito menos, termos projetos políticos que insistem em não atentar para o que há de pedagógico na inclusão das culturas africanas e afro-brasileiras, indispensáveis ao direito dos negros e negras de serem vistos e se reconhecerem, teórica e metodologicamente, nas práticas pedagógicas, ações didáticas e em tudo relacionado ao processo de ensino e aprendizagem.

Importa dizer que o crescimento da população negra na EJA nos revela, principalmente, o quão excludente tem sido a educação escolar aos negros e negras, crianças e jovens, que por diversos motivos fracassaram na aprendizagem, foram abandonados e evadiram dos bancos escolares na etapa de escolarização. Por isso, é importante olharmos para o retrovisor, no sentido de refletirmos sobre a educação que tem sido desenvolvida entre as crianças e os jovens, sobretudo, das classes populares e continuarmos a insistir na modalidade da EJA que assegure aos jovens e adultos o reingresso, com êxito, nos vínculos estabelecidos com a aprendizagem.

Essa é uma das premissas expostas no documento, ao mencionar que:

[...] políticas de reparações voltadas para a educação dos negros devem oferecer garantias a essa população de ingresso, permanência e sucesso na educação escolar, de valorização do patrimônio histórico-cultural afro-brasileiro, de aquisição das competências e dos conhecimentos tidos como indispensáveis para continuidade nos estudos, de condições para alcançar todos os requisitos tendo em vista a conclusão de cada um dos níveis de ensino, bem como para atuar como cidadãos responsáveis e participantes, além de desempenharem com qualificação uma profissão. (BRASIL, 2004, p.11).

Temos dito a respeito da valorização das culturas africanas e as influências afro-brasileiras que precisam ser estudadas e divulgadas entre as concepções científicas e os conhecimentos 
ligados à formação de professores. Ressignificar os conhecimentos de África e reafirmar as manifestações afro-diaspóricas advindas da matriz de seus descendentes é, sobretudo, deslocar o lugar social de superioridade da branquitude pela paridade dos processos pedagógicos que visem promover pedagogias antirracistas e a reeducação das relações étnico-raciais na escola.

As bases epistemológicas, filosóficas e pedagógicas que fundamentam as concepções africanas e afro-brasileiras protagonizam as orientações deixadas nas Diretrizes Curriculares Nacionais para o Ensino de História e Cultura Afro-brasileira e Africana em todos os níveis e modalidades de ensino. Acrescentamos que a riqueza traçada em tantos fios que movem essa rede de conhecimentos, faz parte do esforço individual e coletivo de integrarmos histórias, memórias, tradições, saberes orais, práticas e manifestações culturais, científicas e tecnológicas que nos servem de registros contados [e não-contados] de uma África que estamos por conhecer ou que pouco conhecemos.

Sob vários aspectos, reforçamos a autonomia dos sistemas de ensino e das instituições escolares na produção sistemática de seus projetos pedagógicos e de ensino que versem sobre a diversidade e o respeito às diferenças. Pode não parecer, mas o árduo exercício de reeducação das relações sociais e humanas, sobretudo, étnico-raciais, tem avançado na direção de transformarmos ideias, costumes, atitudes e comportamentos enraizados no preconceito, discriminação e no racismo estrutural, no caso, também, institucional. Nas palavras de Gomes (2005, p. 51):

\begin{abstract}
É por isso que dizemos que as diferenças, mais do que dados da natureza, são construções sociais, culturais e políticas. Aprendemos, desde crianças, a olhar a diversidade humana - ou seja, as nossas semelhanças e dessemelhanças - a partir das particularidades: diferentes formas de corpo, diferentes cores da pele, tipos de cabelo, formatos dos olhos, diferentes formas linguísticas etc.
\end{abstract}

Ao refletirmos a respeito da inclusão da cultura africana e afro-brasileira nos currículos da EJA com base nas DCN's, aproximamos as singularidades dos sujeitos negros da modalidade, 
representados nos conteúdos, falas, imagens, metodologias, bibliografias sugeridas e nas atividades pedagógicas desenvolvidas em salas e extrassalas de aula. Além disso, a temática das relações étnico-raciais, na perspectiva da cultura e diversidade cultural, atende a uma proposta interdisciplinar no currículo escolar, especificamente, planejamentos de ensino, planos de trabalho e situações educativas na EJA que somem na luta pela construção de uma sociedade justa, igualitária e democrática.

Por se tratar de jovens e adultos, negros e negras, o processo interdisciplinar de reeducação das relações étnico-raciais na escola, pressupõe o diálogo com as diferentes abordagens das expressões culturais entre os sujeitos da modalidade. Essa tentativa nos move para o deslocamento e a problematização de determinadas práticas educativas produzidas no cotidiano da escola da EJA que estão enraizadas nas desigualdades culturais e nas dimensões do racismo.

Então, provocamos o diálogo entre as diretrizes curriculares e alguns aspectos considerados encorajadores da reflexão e da superação do poder exercido pela cultura escolar na modalidade. Destacamos a corporeidade afro-brasileira, as expressões da religiosidade de matriz africana, os valores civilizatórios africanos que constituem os modos de ser e de resistir e, por fim, as práticas e manifestações culturais afro-brasileiras.

Nossas preocupações partem de situações que, quase sempre, permanecem naturalizadas pela escola em diversos contextos cotidianos e tornadas, tantas vezes, homogêneas entre os sujeitos jovens e adultos da escola da segunda chance, insistindo na reprodução do currículo escolar pautado na centralidade da branquitude e dos valores eurocêntricos. De um lado, quando reprime vontades, desejos, emoções da pessoa humana, no campo subjetivo; de outro, quando privilegia a padronização e uniformização dos corpos e mentes ao torná-las objeto de controle, vigilância e obediência, no ambiente escolar.

Na base do diálogo interdisciplinar, utilizamos a concepção de corporeidade ligada ao reencontro humano, não apenas dos aspectos físicos e objetivos da matéria [o corpo] como as relações subjetivas estabelecidas nessa integração do espírito, emoção, afeto e valores. Os corpos negros chegam às salas de aula carregados de 
conhecimentos e experiências culturais que favorecem ao entendimento sobre as tradições, os valores da oralidade, a ancestralidade, a espiritualidade e as práticas, assim como das múltiplas linguagens e representações visuais que fazem parte do conteúdo humano, africano e afro-brasileiro. (AHLERT, 2010).

A expressão dos corpos e movimentos libertários, espontâneos e autônomos, herdados das experiências de África e da diáspora podem ser percebidos nas representações visuais, seja no embelezamento e potência dos cabelos, nas cores vivas dos tecidos, nos acessórios da moda africana, na riqueza artística da música, literatura, dança, entre outros aspectos que influenciam [e influenciaram] a cultura afro-brasileira. Essa é uma das razões para ressignificarmos os corpos e as mentes dos que estão nas salas de aula das escolas de jovens e adultos pois, sistematicamente, passaram pela experiência do silenciamento e da opressão nos tantos projetos curriculares voltados para a cultura da obediência e controle rígido do ensino regular.

Reeducar as relações étnico-raciais pressupõem abolirmos alguns ritos da cultura escolar que mais reproduzem a disciplinarização, a obediência e a repressão que lembram os processos de privação a que negros e negras foram submetidos. De modo ambíguo, quando falamos da escola de adultos, pressupomos que está fundamentada na liberdade dos sujeitos da EJA, tanto nos discursos como nas práticas acadêmicas progressistas. No entanto, a realidade, ainda, reforça as normas disciplinares incondicionais de controle e vigilância sob esses mesmos corpos sem consultá-los ou dar-Ihes autonomia nas escolhas. Lembremos do rito de entrada nos portões da escola pela rigidez do tempo, do uso incontestável do uniforme ou farda, da sincronia estabelecida no comportamento do sentar/levantar-se, a partir de comandos e tantos outros mandos que são repetidos nessa modalidade de educação constituída por pessoas jovens, adultas e idosas.

Sabemos que a formação da identidade da criança, jovem, adulto está ligada à apreensão de normas, regras e condutas sociais, mas de modo algum podemos esquecer do passado de privação das expressões do corpo vividas pelo povo negro em suas manifestações e trocas culturais, assumidamente, desumanas. Oyěwùmí (1997, p.3) 
nos diz que "o corpo está sempre em vista e à vista". No caso da EJA, os sentidos da vida, as percepções de mundo e a sensibilidade das emoções servem de força para a humanização das relações estabelecidas dentro e fora da escola e, principalmente, como aproximação do sujeito às múltiplas possibilidades de aprendizagem.

A concepção dialógica e interdisciplinar das expressões simbólicas, conceituais e estruturais do currículo escolar em relação aos jovens e adultos, negros e negras da modalidade, consistem no reconhecimento das diferentes raízes de matrizes africana e afrobrasileira e na mudança de um novo olhar sobre as culturas e grupos étnicos-raciais diversos, como é o caso das religiões de raiz africana e afro-brasileiras.

No exercício político e social de compreendermos as relações étnico-raciais, no campo das diretrizes, damos ênfase à questão das religiões tradicionais africanas relacionadas com outras culturas que subsidiam inúmeras discussões, no caso dos conhecimentos ancestrais, valores espirituais, simbólicos e, sobretudo, encontro das religiões afro-brasileiras. Então, os processos pedagógicos promovidos no interior das salas de aula devem ser conduzidos em favor do que as DCN's nos indicam quanto a

[...] valorização e respeito às pessoas negras, à sua descendência africana, sua cultura e história. Significa buscar, compreender seus valores e lutas, ser sensível ao sofrimento causado por tantas formas de desqualificação: apelidos depreciativos, brincadeiras, piadas de mau gosto sugerindo incapacidade, ridicularizando seus traços físicos, a textura de seus cabelos, fazendo pouco das religiões de raiz africana. Implica criar condições para que os estudantes negros não sejam rejeitados em virtude da cor da sua pele, menosprezados em virtude de seus antepassados terem sido explorados como escravos, não sejam desencorajados de prosseguir estudos, de estudar questões que dizem respeito à comunidade negra. (BRASIL, 2004, p.12).

Consideramos fundamental incluirmos no debate, os espaços dos terreiros - candomblé e umbanda - como lócus não formais de 
produção de sentidos e conhecimentos ou como "educação nos terreiros" (CAPUTO, 2012), pois reúnem jovens e adultos com saberes próprios, específicos e afro-religiosos. É bom que se diga que no chão de terra batida das religiões de matriz africana estão as marcas da luta e da resistência do povo negro, africano e afro-brasileiro, na recuperação de sua história, preservação da memória e constituição da cultura nacional.

Ao falarmos das manifestações afro-religiosas praticadas no interior desses espaços, problematizamos os cenários e as múltiplas possibilidades de abordagens desse tema que, de tão amplo e diverso, nos sugere tratar das experiências cosmológicas e celestiais ligadas aos elementos da natureza (água, ar, fogo, terra) com as nossas cosmopercepções" ${ }^{\prime 7}$. (MACHADO; PETIT, 2018, p.10). Em outras palavras, o corpo inteiro fala e sente, desde a relação dos pés descalços em contato com o chão batido do Xirê ${ }^{8}$ à sincronia da circularidade, o ritmo dos tambores, a ginga nos movimentos da dança, os mistérios dos ritos e das celebrações, o poder das palmas e a sintonia dos corpos, a música com suas letras, o pulsar dos corpos em contato com a energia espiritual, o respeito à ancestralidade, a reverência aos mais velhos na hierarquia do santo, entre outras situações que nos 'africanizam'. (OLIVEIRA, 2006).

Alguns pontos destacados, mostram a complexidade de se trabalhar as culturas [africanas e afro-brasileiras] na travessia das práticas interdisciplinares, pois envolvem o plano físico/material do plano espiritual/imaterial. A ênfase na questão religiosa não está no detalhamento do que ocorre nas rodas dos terreiros, mas na reflexão acerca do público negro, jovem e adultos, que carrega o pertencimento étnico-racial como parte de suas histórias ligadas às religiões de raiz africana e afro-brasileira e estão presentes nas salas de aula da EJA, quase sempre, sem serem vistos, reconhecidos e legitimados nas práticas pedagógicas.

Vemos que são muitos desafios da realidade social, história e cultural nos currículos oficiais - colonizadores e eurocentrados - e

${ }^{7}$ Definimos as cosmopercepções como "modos de perceber e sentir, pensar de corpo inteiro; em outras palavras: corpo e pensamento em ação". (MACHADO; PETIT, 2018, p.10).

${ }^{8}$ Em Yorubá, a palavra Xirê significa roda. (www.wikipedia.org.br) 
apoiamos os princípios norteadores das diretrizes curriculares que sustentam a valorização da diversidade e o respeito aos processos históricos de resistência negra. Então, a educação nos terreiros que nos referimos, entre muitas razões, mostra o quanto seus praticantes e suas práticas, dentro e fora da escola, "dão continuidade a uma tradição viva, afirmam identidades, sentem orgulho da tradição em que vivem, constroem e reconstroem autoimagens". (CAPUTO, 2012, p.21).

O contexto interdisciplinar das experiências afro-religiosas na escola [e fora dela], nos desafia a pensar em rupturas epistemológicas dos conhecimentos que operam na lógica dos isolamento e fragmentação dos saberes, pelas trocas da experiência integrada e integral dos conteúdos, ensinamentos e valores encarnados nas crenças e nos sujeitos-praticantes das religiões de matriz africana. São muitas articulações entre os conhecimentos desenvolvidos nos campos da aprendizagem, como é possível analisar na passagem de Moura (2017, p. 112-113):

[...] vários registros são acionados simultaneamente na vivência prática desses saberes, uma vez que, para se entender de danças, por exemplo, é preciso dos toques das cantigas, que, no caso de um terreiro de candomblé, invariavelmente envolve a capacidade de articular minimamente o yorubá. Desse modo, saudar uma divindade por meio da dança implica mobilizar um conjunto de conhecimentos linguísticos, corporais, musicais, estéticos, que só se aprende no processo que se estabelece desde o primeiro momento de inserção em um terreiro e que perpassa pelo estabelecimento de relações com as demais filhas de santo e, principalmente, com aquelas que ocupam níveis hierárquicos mais elevados dentro da organização da religião, ou mais tempo em contato com o universo afro-religioso.

É na resistência dos currículos escolares e na abertura para novas, e não tão novas epistemologias e práticas científicas e pedagógicas, que encontramos um oceano de possibilidades para a tessitura dos conhecimentos afro-religiosos aliadas à imensidão de 
saberes e conteúdos escolares necessários à aprendizagem dos jovens e adultos, negros e negras. "O que sabemos a respeito de tantas manifestações culturais africanas e afro-brasileiras disseminadas entre muitas comunidades de aprendizagem e de seus sujeitos-praticantes?" (FERREIRA; RUBIM, 2019). As inúmeras tentativas de respostas passam pelo reconhecimento da diversidade e na afirmação da identidade cultural; questionamento da desigualdade étnico-racial, sobretudo, nos aspectos afro-religiosos; reparação das estruturas sociais que hierarquizam, reforçam a depreciação em relação aos negros e reafirmam estereótipos que diminuem e silenciam as pessoas. Dependem, também, da correção do abismo das desvantagens culturais e da exclusão social que impedem a troca com o Atlântico e seus descendentes.

A afirmativa utilizada por Falola (2020, p.443) nos convence de que "quanto mais pessoas souberem quem somos, africanos no continente e na diáspora, talvez elas aprendam pouco a pouco a nos valorizar". Logo, por diversos fatores, potencializamos as culturas ligadas ao povo negro, consciente de suas histórias, valores, conhecimentos e experiências de luta e de resistência, como fundamentos para a descolonização de saberes e fazeres presentes nas salas de aula da modalidade.

A ressignificação que queremos com a educação das relações étnico-raciais não esgota as possibilidades de muitas Áfricas espalhadas nas escolas brasileiras e, de modo restrito, nas identidades da negritude produzidas pela diáspora africana que permanece presente e mantém viva as expressões e manifestações das culturas. Embora a reeducação das relações étnico-raciais não seja tarefa exclusiva da escola, os espaços das salas de aula desempenham importante papel na desalienação dos processos pedagógicos e, sobretudo, na descolonização dos currículos etnocentrados na branquitude do europeu.

\section{CONSIDERAÇÕES FINAIS}

Os estudos que tratam da educação das relações étnicoraciais têm nos revelado um árduo exercício de ruptura com as epistemologias tradicionais, conservadoras e práticas enraizadas em 
valores que reproduzem a opressão, o racismo e tantas outras formas de exclusão social. Vemos que a compreensão sobre as relações sociais ligadas às questões raciais e identitárias estão mergulhadas na diversidade e resultam no atravessamento da educação em todos sentidos dados à humanização e a vida.

Ao discutirmos as questões étnico-raciais nos processos educativos, não é novidade a alteração da LDBEN 9.394/1996, em 2003, pela implementação da Lei 10.639/2003 e o surgimento das Diretrizes Curriculares Nacionais que tratam da inclusão da temática afro-brasileira nos currículos da educação básica. Isso significa que, embora seja uma das importantes conquistas do movimento negro e das entidades ligadas às políticas públicas de educação em favor do povo negro, ainda não são suficientes para declararmos o fim da luta antirracista, na escola e fora dela, por uma democracia racial na sociedade brasileira. Ao contrário, assistimos [ainda] currículos e práticas educacionais flagrantes no distanciamento, negação e/ou apagamento histórico, político e cultural não corrigidos ao longo desses anos.

Essas razões explicam o uso da expressão "reeducação" por tratar-se de um processo que, reiteradas vezes, se repete e se renova no âmbito das relações socio-culturais-educacionais. Então, a reeducação das relações étnico-raciais resgata a história construída nas marcas da luta e reconhece os avanços de uma África que resiste ao tempo, revigora movimentos dinâmicos de preservação da cultura e que se adapta ao presente nas interações com outros grupos étnico-raciais e grupos sociais diversos.

Nesse movimento contínuo e permanente, não cabe naturalizar a questão étnico-racial na escola sem impacto político, reflexivo e transformador de pensares e fazeres, mesmo que o caminho ainda seja longo, temos, a consciência da cidadania que está encarnada nos sujeitos que reconhecem, em si, suas identidades como pessoas negras, jovens e adultos e que, por meio da educação passam a compreender as diferenças como necessárias ao projeto democrático de sociedade. (GOMES, 2011).

Por esse motivo, partimos do pressuposto que a educação das relações étnico-raciais, em um primeiro momento, apontada nas diretrizes curriculares não alcança as questões mais profundas acerca 
do conhecimento de e sobre a história e as culturas de África. Por outro lado, nos permite compreender as transformações, adaptações e influências (con)sentidas nas culturas afro-brasileiras em diversos aspectos - históricos, políticos, culturais e sociais - que nos auxiliam no trabalho de superação dos conhecimentos enraizados nas violências simbólicas (quando não, explícitas), preconceitos e nos racismos.

Na mesma tentativa, problematizamos os registros oficiais das matrículas na Educação de Jovens e Adultos acompanhados dos números do Censo Educacional com a afirmação das identidades negras, constatadas nas categorias raciais e posições fenotípicas informadas - brancos, pretos, pardos, amarelos e indígenas. Além do crescimento de pessoas que se autoafirmam e autodeclaram, negros e negras, na Educação de Jovens e Adultos, muitas expressões de suas referências pessoais e coletivas refletem parte dos avanços positivos desse processo de construção da identidade do povo negro, fundamental, na ampliação do debate e luta antirracista, igualitária e democrática.

Sabemos que a questão do pertencimento biológico centrado na marcação racial vai muito além do tingimento físico da cor da pele ou dos traços da negritude, pois envolve a construção social produzida nas redes de sociabilidade, grupos de interação, canais de comunicação e movimentos que reivindicam maior visibilidade social nas inúmeras manifestações identitárias negras. É o que Gomes (2005, p.43) nos diz a respeito da identidade negra como "uma construção social, histórica, cultural e plural. Implica a construção do olhar de um grupo étnico/racial ou de sujeitos que pertencem a um mesmo grupo étnico/racial, sobre si mesmos, a partir da relação com o outro".

Desse modo, consideramos a autonomia na escolha das categorias raciais informadas no ato da matrícula, um ponto de partida muito importante no processo de legitimidade da identidade negra na escola. Dito de outra forma, reconhecer-se negro, preto ou pardo é, provavelmente, para muitos, o início do anúncio de um fortalecimento identitário e, ao mesmo tempo, a denúncia contra as formas explícitas (e implícitas) de discriminação e desigualdade, produzidas, historicamente, na lógica da unidade e da 
homogeneização racial, resultado do racismo estrutural e institucional.

Parece-nos que, passados os anos da promulgação da Lei 10.639/2003 e implementação das DCN's para a Educação das Relações Étnico-Raciais, o enraizamento e a herança histórica e cultural das populações negras africanas ainda representam um árduo caminho no debate educacional sobre o currículo escolar e as práticas pedagógicas desenvolvidas a partir dessa temática, necessária e fundamental, na garantia da igualdade de direitos das populações negras se reconhecerem e serem vistas em suas culturas, de forma comprometida e democrática pelos sistemas educacionais.

Chama a atenção, a afirmativa de Falola $(2020$, p. 19) de que "a cultura tem sido a principal fonte para a construção da identidade e para a reinvenção da nação e da etnicidade em face da imposição colonial e das mudanças decorrentes dela".

Mais que isso, a constatação das identidades negras informadas e autodeclaradas entre os jovens e adultos, negros e negras da EJA, marcam não somente pelo motivo suficiente para o diálogo interdisciplinar entre as diretrizes curriculares e alguns aspectos das culturas africanas e afro-brasileiras. Também nos leva a problematizar e mudar o olhar sobre as questões étnico-raciais na escola, resgatando parte das origens históricas e culturais presentes na identidade da negritude que, por si só, merecem atenção dos projetos políticos e pedagógicos, dos conhecimentos previstos no currículo e, principalmente, nas ações didáticas desenvolvidas na modalidade.

Sem esgotarmos o debate, é preciso que os currículos forjados na branquitude e nos valores ocidentais deem lugar às discussões críticas que aprofundem as culturas africanas e afrobrasileiras. É possível problematizar aspectos ligados à dimensão da corporeidade, africana e afro-brasileira, tornada invisível e negada nas salas de aula da EJA; às múltiplas abordagens das religiosidades de matriz africana; às inúmeras manifestações e práticas culturais de raiz africana conectadas com as experiências de seus descendentes brasileiros. 


\section{REFERÊNCIAS}

AHLERT, Alvori. Corporeidade e educação: o corpo e os novos paradigmas da complexidade. Espacios en Blanco. Revista de Educación, v. 21, p. 219-224, jun, 2010, Disponível em: https://www.redalyc.org/pdf/3845/384539803009.pdf. Acesso em 18 jan. 2021.

BRASIL. Lei no 9.394, de 20 de dezembro de 1996. Estabelece as Diretrizes e Bases da Educação Nacional. Diário Oficial da União: Brasilia, DF, 23 dez. 1996. Disponível em: http://www.planalto.gov.br/ccivil_03/leis//9394.htm. Acesso em: 13 jan. 2021.

BRASIL. Instituto Nacional de Estudos e Pesquisas Educacionais Anísio Teixeira (Inep). Censo da Educação Básica 2019: Resumo Técnico. Brasília, 2020.

BRASIL. Conselho Nacional de Educação. Ministério da Educação. Diretrizes Curriculares Nacionais para a Educação das Relações Étnico-Raciais e para o Ensino de História e Cultura Afro-Brasileira e Africana. Brasília, 2004. Disponível em: http://portal.mec.gov.br/cne/arquivos/pdf/003.pdf. Acesso em: 15 fev. 2021.

BRASIL. Lei no 9.394, de 20 de dezembro de 1996. Estabelece as Diretrizes e Bases da Educação Nacional. Brasília, 1996. Disponível em: http://www.planalto.gov.br/CCIVIL_03/LEIS/L9394.htm. Acesso em: 18 fev. 2021.

BRASIL. Lei no 10.639/2003, de 9 de janeiro de 2003. Altera a Lei $n^{\circ}$ 9. 394, de 20 de dezembro de 1996. Diário Oficial da União: Brasilia, DF, 10 jan. 2003. Disponível em: http://www.planalto.gov.br/ccivil_03/leis/2003/l10.639.htm. Acesso em: 18 fev. 2021.

CAPUTO, Stela Guedes. Educação nos terreiros: e como a escola se relaciona com crianças de candomblé. Rio de Janeiro: Pallas, 2012.

FALOLA, Toyin. 0 poder das culturas africanas. Petrópolis, RJ: Vozes, 2020. 
FERREIRA, Luís Carlos; RUBIM, Cristina Varandas. Comunidades que ensinam e Adultos que aprendem: a Educação Moçambicana de Adultos no debate com as comunidades de aprendizagem. Revista Aquila, v. 21, p. 265-284, 2019. Disponível em:

https://ojs.uva.br/index.php/revista-aquila/article/view/40. Acesso em 05 fev. 2021.

GENTILI, Pablo. Educação e cidadania: a formação ética como desafio político. In: GENTILI, Paulo; ALENCAR, Chico. Educar na esperança em tempos de desencanto. Petrópolis, RJ: Editora Vozes, 2005.

GOMES, Nilma Lino. Alguns termos e conceitos presentes no debate sobre relações raciais no Brasil: uma breve discussão. História.

Coleção para todos. Secretaria de Educação Continuada, Alfabetização e Diversidade. Brasília: Ministério da Educação 2005.

GOMES, Nilma Lino. Educação de Jovens e Adultos e questão racial: algumas reflexões iniciais. In: SOARES, Leôncio; GIOVANETTI, Maria Amélia Gomes de Castro; GOMES, Nilma Lino. Diálogos na educação de jovens e adultos. Belo Horizonte: Autêntica Editora, 2011.

MACHADO, Adilbênia Freire; PETIT, Sandra Haydée. Filosofia africana para afrorreferenciar o currículo e o Pertencimento. Revista Exitus, Santarém/PA, v. 10, p. 01-31, 2020. ISSN 2237-9460. Disponível em: http://www.ufopa.edu.br/portaldeperiodicos/index.php/revistaexitus . Acesso em: 11 jan. 2021.

MOURA, Beatriz Martins. "Aqui a gente tem folha": Terreiros de religiões de matriz africana como espaços de articulação de saberes. Dissertação (Mestrado em Antropologia), Universidade de Brasília, Brasília, 2017.

MARTINS, Ernesto Candeias. A corporeidade na aprendizagem escolar (Entrelaços fenomenológicos do pensar e agir). Educar em Revista, Curitiba, Editora UFPR, n. 56, p. 163-180, abr./jun,2015. Disponível em: https://www.scielo.br/j/er/a/TZvQfbWjYc757XpyYJrvFLM/?lang=pt\&f ormat=pdf. Acesso em: 05 fev. 2021. 
ODÉ INOCÊNCIO, Nelson. Representação visual do corpo afrodescendente. In: PANTOJA, Selma (org.) et alii. Entre Áfricas e Brasil. Brasília: Paralelo. São Paulo, Marco Zero, 2001.

OLIVEIRA, Eduardo. Cosmovisão Africana no Brasil: elementos para uma filosofia afrodescendente. Curitiba: Gráfica e Editora Popular, 2006.

OYĚWÙMí, Oyèrónké. Visualizando o corpo: teorias ocidentais e sujeitos africanos. Tradução: Leonardo de Freitas Neto, UFRB.

Revista do PPGCS, UFRB, Novos Olhares Sociais, v.1, n. 2, 2018.

SANTOS, Boaventura de Souza. Hermenêutica diatrópica. Pela democratização do conhecimento. Entrevista a Jurandir Malerba. Registro. Caderno Especial. Universidade Federal de Ouro Preto (Ufop) (Centro Nacional de Referência Historiográfica), ano 3, n. 5 , mar./ago.1996.

SCHWARCZ, Lilia Mortiz. Nem preto nem branco, muito pelo contrário: cor e raça na sociabilidade brasileira. São Paulo: Claro Enigma, 2012.

Submetido em: Junho/2021.

Aceito em: Julho/ 2021. 